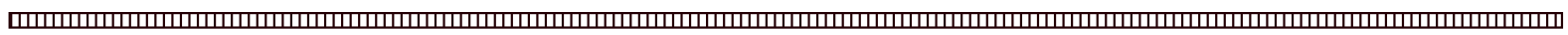

\title{
Ciencias Sociales y Humanidades
}

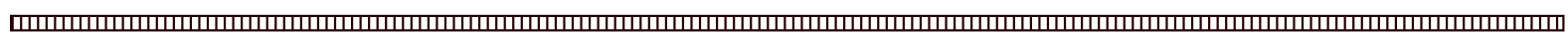

ISSN: $2409-3475$

Volumen 6 Número 1 enero / junio 2019

\section{Presentación / Presentation}



Q uiero con estas letras dar inicio agradeciendo la confianza depositada por nuestra máxima autoridad, el rector magnifico Murphy Paiz, en delegar en mi persona la coordinación de esta Dirección General de Investigación, DIGI. Es precisamente recogiendo el interés de nuestra rectoría de apoyar la investigación y el resultado de estos esfuerzos que nos sumamos a la iniciativa de la Revista Ciencias Sociales y Humanidades. Arrastrando este país aun problemas estructurales que castigan y aletargan nuestro desarrollo, estamos consientes del papel central que juegan las ciencias sociales como una herramienta para frenar el subdesarrollo y para la búsqueda de rutas que respondan a estos problemas. Una de estas vías es la investigación, y la otra el acceso abierto de estos esfuerzos. Ambas iniciativas son recogidas en mi gestión, por lo que desde nuestro espacio brindamos el apoyo necesario para la continuidad de este esfuerzo.

Ing. Agr. Manuel de Jesús Martínez Ovalle Director General de Investigación Universidad de San Carlos de Guatemala 